Pacific Journal of Mathematics

UNIQUE FACTORIZATION IN POWER SERIES RINGS AND

N DECKARD AND LINCOLN KEARNEY DURST 


\title{
UNIQUE FACTORIZATION IN POWER SERIES RINGS AND SEMIGROUPS
}

\author{
Don DeCKard and L. K. Durst
}

In this note a short proof is given for a theorem due originally to Deckard and to Cashwell and Everett. The theorem states that every ring of power series over an integral domain $R$ is a unique factorization domain if and only if every ring of power series over $R$ in a finite set of indeterminates is a unique factorization domain. The proof is based on a study of the structure of the multiplicative semigroups of such rings. Much of the novelty and most of the brevity of this argument may be accounted for by the fact that Dilworth's theorem on the decomposition of partially ordered sets is invoked at a crucial point in the proof.

Suppose $R$ is a ring and that $R^{+}$is the additive group of $R$. Suppose $I$ is a nonvoid set well ordered by $<$. If $N$ is the additive semigroup of the nonnegative integers and $M$ is the weak product (Chevalley [3]) $\prod_{i \in I}^{w} N$, let $R_{I}=\prod_{m \in M} R^{+}$. For $f, g$ in $R_{I}$ define

$$
(f g)(m)=\sum_{k+l=m} f(k) g(l) ;
$$

the resulting ring is called a ring of power series over $R$, and is an integral domain if $R$ is. An $f$ in $R_{I}$ is a unit if and only if $f(0)$ is a unit of $R$.

Deckard [5] and Cashwell and Everett [2] proved that $R_{I}$ is a unique factorization domain for every $I$ if $R_{J}$ is a unique factorization domain for every finite set $J$. (Thus it follows, from results of Samuel [8] and Buchsbaum [1], that $R_{I}$ is a unique factorization domain if $R$ is a regular unique factorization domain.)

It suffices to consider either the multiplicative semigroup $S_{I}$ of the nonzero members of $R_{I}$ or the quotient of $S_{I}$ obtained by identifying associates; factorization in a cancellative semigroup being unique if and only if (Clifford [4]) both

(1) The divisor chain condition holds.

(2) All irreducibles are primes.

This note contains a study of factorization in a class of semigroups which, on specialization, yields a direct and concise proof of the Deckard-Cashwell and Everett theorem.

Extensions of semigroups. With $I$ as above, suppose $\left\{S_{i}: i \in I\right\}$

Received May 8, 1964. 
is a family of commutative cancellative semigroups indexed by $I$, and that

(a) For each pair $i, j$ of members of $I$, if $i<j, S_{j}$ contains a nonvoid prime coideal (MacKenzie [7]) $C_{i}^{j}$ and $C_{i}^{k} \subseteq C_{j}^{k}$ if $i<j<k$.

(b) If $i, j$ are in $I$ and $i<j$, there is an epimorphism $h_{i}^{j}: C_{i}^{j} \rightarrow S_{i}$ with $h_{i}^{k}=h_{i}^{j} \circ h_{j}^{k}$ if $i<j<k$.

(c) $\left(h_{i}^{j}\right)^{-1} U_{i}=U_{j}$ for $i<j$, where $U_{i}$ is the group of units of $S_{i}$. Let $S$ be the set of all $f$ in $\bigcup_{i \in I} \prod_{j \in I}^{i \leq j} S_{j}$ for which

(d) $f(j) \in C_{i}^{j}$ for $i<j$ if and only if $I=\operatorname{Dom} f$ or $\operatorname{Inf} \operatorname{Dom} f<$ $i \in \operatorname{Dom} f$.

(e) $f(i)=h_{i}^{j} f(j)$ if $i \in \operatorname{Dom} f$ and $i<j$.

With the definition $(f g)(i)=f(i) g(i)$ for $i \in(\operatorname{Dom} f) \cap(\operatorname{Dom} g), S$ is a semigroup. Suppose, finally, that

(f) For each $k$ in $I$, if there exist $u_{i}$ in $U_{i}$ for $i<k$ satisfying $u_{i}=h_{i}^{j} u_{j}$ whenever $i<j<k$, then there is a $u$ in $S$ such that $u(i)=$ $u_{i}$ for $i<k$.

In view of condition (c) the $u$ in condition (f) clearly belongs to $U$, the group of units of $S$. In the power series case a much stronger version of condition (f) holds. However, for present purposes, it is sufficient to assume (f) only for units.

It will be convenient to refer to $S$ as the extension of the family $\left\{S_{i}: i \in I\right\}$.

Divisor chain condition. If $J \subseteq I$ and if $J$ has no upper bound in $I, J$ will be said to contain "arbitrarily large" members of $I$.

Lemma 1. $S$ satisfies the divisor chain condition if, for arbitrarily large $i, S_{i}$ satisfies the divisor chain condition.

Assume, indeed, that $f^{(k)} \in S$ and $f^{(k+1)} \mid f^{(k)}$ for $k=0,1,2, \ldots$. If $f^{(l)} g^{(l, n)}=f^{(n)}$ for $l>n$, then, for $i$ sufficiently large, $f^{(l)}(i) g^{(l, n)}(i)=$ $f^{(n)}(i)$ if $l>n$. Thus for $n$ sufficiently large, $g^{(l, n)}(i) \in U_{i}$ for some $i$ if $l>n$. Hence, by $(c), g^{(l, n)} \in U$ if $l>n$ and $n$ is sufficiently large.

Interpolation and primes. Suppose $J$ is a subset of $I$ containing arbitrarily large members of $I$ and that for each $i$ in $J$ there is an $f_{i}$ such that $f_{j} \in C_{i}^{j}$ and $f_{i}=h_{i}^{j} f_{j}$ if $i, j$ in $J$ and $i<j$. Using $h_{i}^{k}=h_{i}^{j} \circ h_{j}^{k}$ if $i<j<k, f_{i}$ can be defined on an upper segment of $I$ containing $J$, determining a unique $f$ of $S$ such that $f(i)=f_{i}$ for $i \in J$.

LEMMA 2. If $p \in S$ and if, for arbitrarily large $i, p(i)$ is a prime in $S_{i}$, then $p$ is a prime in $S$. 
If $f, g$ are in $S$ and $p \mid f g$, then for sufficiently large $i, p(i) \mid f(i) g(i)$; and for arbitrarily large $i, p(i) \mid f(i)$ or $p(i) \mid g(i)$. If $p(i) q_{i}=f(i)$ for arbitrarily large $i$, then $h_{i}^{j} q_{j}=q_{i}$ if $i<j$ for $i, j$ in an unbounded subset of $I$, so there is a $q$ in $S$ for which $p q=f$.

Identification of associates. If $\bar{S}_{i}$ and $\bar{C}_{i}^{j}$ are, respectively, the quotients of $S_{i}$ and $C_{i}^{j}$ obtained by identifying associates and if $\bar{h}_{i}^{j}$ : $\bar{C}_{i}^{j} \rightarrow \bar{S}_{i}$ are the corresponding homomorphisms generated by the $h_{i}^{j}$, it follows that conditions (a)-(f) remain valid for these "reduced" semigroups. Let $\bar{S}$ be the quotient of $S$ and let $S^{\prime}$ be the extension of the $\bar{S}_{i}$.

\section{Lemma 3. $\bar{S}$ and $S^{\prime}$ are isomorphic.}

For $f$ in $S$, write $\bar{f}$ for the member of $\bar{S}$ containing $f$ and $\overline{f(i)}$ for the member of $\bar{S}_{i}$ containing $f(i)$, and define the map $\varphi: \bar{S} \rightarrow S^{\prime}$ by $(\varphi \bar{f})(i)=\overline{f(i)}, i \in \operatorname{Dom} f$. It is easy to see that $\varphi$ is a monomorphism. An induction argument shows that $\varphi$ is surjective. Indeed, suppose $g \in S^{\prime}$ : to find $f$ in $S$ satisfying $f \overline{(i)}=g(i)$ for $i \in$ Dom $g$. Let $i_{g}=\operatorname{Inf} \operatorname{Dom} g$, pick $f_{i_{g}}$ in $g\left(i_{g}\right)$ and suppose that for $i_{g} \leqq i<k$ there are $f_{i}$ in $g(i)$ satisfying $h_{\imath}^{j} f_{j}=f_{i}$ whenever $i_{g} \leqq i<j<k$. If $s \in g(k)$, then, for $i_{g} \leqq i<k, h_{\imath}^{k} s=u_{i} f_{i}$ where $u_{i} \in U_{i}$. Here $u_{i}=h_{i}^{j} u_{j}$ for $i<j<k$, and by condition (f) there is a $u$ in $U$ satisfying $h_{\imath}^{k}(u(k))=$ $u_{i}$ for $i<k_{\text {. }}$. If $f_{k}=[u(k)]^{-1} s$, then $h_{\imath}^{k}\left(f_{k}\right)=u_{\imath}^{-1} h_{\imath}^{k}(s)=f_{i}$. By induction, there is an $f$ in $S$ satisfying $f(i)=f_{i}$ and $\varphi \bar{f}=g$.

Reducibility. If $f \in S$ say that $f$ is normal if, for arbitrarily large $i, f(i)$ has a unique representation in $S_{i}$ as a product of irreducibles.

LEMma 4. If $f$ is normal then $f$ is reducible in $S$ if, for arbitrarily large $i, f(i)$ is reducible in $S_{i}$.

In view of Lemma 3 associates may be identified. Suppose, then, that $J$ is an unbounded subset of $I$ and that for each $j$ in $J, f(j)$ has a unique representation

$$
f(j)=a_{j}^{(1)} \cdots a_{j}^{\left(n_{j}\right)}
$$

where each $\alpha_{j}^{(k)}$ is an irreducible in $S_{j}$. If $i \in J$ and $i<j$

$$
f(i)=\prod_{1}^{n_{i}} a_{i}^{(l)}=\prod_{1}^{n_{i}} h_{i}^{j} a_{j}^{(l)}
$$

so $n_{i} \geqq n_{j}$ and for sufficiently large $j$ in $J, n_{j}$ is a constant $n$ depend- 
ing only on $f$. By hypothesis, $n \geqq 2$. Hence, for each $i$ in some unbounded subset $K$ of $I, f(i)$ is a product of exactly $n$ irreducibles. In the set $P$ of all irreducible factors of $f(i)$ with $i \in K$ define

$$
a \prec b \text { if } a=h_{\imath}^{j} b \text { for some } i, j \text { in } K, i<j \text {. }
$$

The relation $\prec$ is transitive by condition (b) and thus defines a partial order in $P$. However each subset of $P$ with more than $n$ members contains a comparable pair and thus, by a theorem of Dilworth [6], $P$ is the union of $n$ or fewer chains. At least one such chain is unbounded and determines in $S$ a proper factor of $f$.

THEOREM. In $S$ factorization into irreducibles is unique if, for arbitrarily large $i$, factorization into irreducibles in $S_{i}$ is unique.

Proof. By Lemma 1, $S$ satisfies the divisor chain condition. It remains to show that in $S$ all irreducibles are primes. Suppose $p \in S$ and $p$ is irreducible. Then, by Lemma $4, p(i)$ is irreducible in $S_{i}$ for some $i$, since every member of $S$ is normal. In view of condition (c), $p(i)$ is irreducible in $S_{i}$ for all sufficiently large $i$. But then, $p(i)$ is prime in $S_{i}$ for $i$ arbitrarily large and, by Lemma $2, p$ is prime in $S$.

\section{REFERENCES}

1. D. A. Buchsbaum, Some remarks on factorization in power series rings, J. Math. Mech. 10 (1961), 749-753.

2. E. D. Cashwell and C. J. Everett, Formal power series, Pacific J. Math. 13 (1963), 45-64.

3. Claude Chevalley, Fundamental Concepts of Algebra, New York, Academic Press, 1956.

4. A. H. Clifford, Arithmetic and ideal theory of Commutative Semigroups, Ann. Math.

(2) 39 (1938), 594-610.

5. D. J. Deckard, M. A. Thesis, Rice University, 1961.

6. R. P. Dilworth, A decomposition theorem for partially ordered sets, Ann. Math. (2)

51 (1950), 161-166.

7. R. E. MacKenzie, Commutative semigroups, Duke Math. J. 21 (1954), 471-478.

8. Pierre Samuel, On unique factorization domains, Illinois J. Math. 5 (1961), 1-17.

RICE UNIVERSITY 


\section{PACIFIC JOURNAL OF MATHEMATICS}

\section{EDITORS}

\section{H. SAMELSON}

Stanford University

Stanford, California

\section{R. M. BLUMenthaL \\ University of Washington \\ Seattle, Washington 98105}

*J. DugundjI

University of Southern California Los Angeles, California 90007

\section{RICHARD ARENS}

University of California

Los Angeles, California 90024

\section{ASSOCIATE EDITORS}
E. F. BECKENBACH
B. H. NeUManN
F. WOLF
K. YosIDA

\section{SUPPORTING INSTITUTIONS}

\author{
UNIVERSITY OF BRITISH COLUMBIA \\ CALIFORNIA INSTITUTE OF TECHNOLOGY \\ UNIVERSITY OF CALIFORNIA \\ MONTANA STATE UNIVERSITY \\ UNIVERSITY OF NEVADA \\ NEW MEXICO STATE UNIVERSITY \\ OREGON STATE UNIVERSITY \\ UNIVERSITY OF OREGON \\ OSAKA UNIVERSITY \\ UNIVERSITY OF SOUTHERN CALIFORNIA
}

\author{
STANFORD UNIVERSITY \\ UNIVERSITY OF TOKYO \\ UNIVERSITY OF UTAH \\ WASHINGTON STATE UNIVERSITY \\ UNIVERSITY OF WASHINGTON \\ AMERICAN MATHEMATICAL SOCIETY \\ CHEVRON RESEARCH CORPORATION \\ TRW SYSTEMS \\ NAVAL ORDNANCE TEST STATION
}

Mathematical papers intended for publication in the Pacific Journal of Mathematics should be typewritten (double spaced). The first paragraph or two must be capable of being used separately as a synopsis of the entire paper. It should not contain references to the bibliography. Manuscripts may be sent to any one of the four editors. All other communications to the editors should be addressed to the managing editor, Richard Arens at the University of California, Los Angeles, California 90024.

50 reprints per author of each article are furnished free of charge; additional copies may be obtained at cost in multiples of 50 .

The Pacific Journal of Mathematics is published monthly. Effective with Volume 16 the price per volume (3 numbers) is $\$ 8.00$; single issues, $\$ 3.00$. Special price for current issues to individual faculty members of supporting institutions and to individual members of the American Mathematical Society: $\$ 4.00$ per volume; single issues $\$ 1.50$. Back numbers are available.

Subscriptions, orders for back numbers, and changes of address should be sent to Pacific Journal of Mathematics, 103 Highland Boulevard, Berkeley 8, California.

Printed at Kokusai Bunken Insatsusha (International Academic Printing Co., Ltd.), No. 6, 2-chome, Fujimi-cho, Chiyoda-ku, Tokyo, Japan.

PUBLISHED BY PACIFIC JOURNAL OF MATHEMATICS, A NON-PROFIT CORPORATION

The Supporting Institutions listed above contribute to the cost of publication of this Journal, but they are not owners or publishers and have no responsibility for its content or policies.

* Paul A. White, Acting Editor until J. Dugundji returns. 


\section{Pacific Journal of Mathematics}

\section{Vol. 16, No. 2 December, 1966}

Loren N. Argabright, Invariant means on topological semigroups ........ 193

William Arveson, A theorem on the action of abelian unitary groups ...... 205

John Spurgeon Bradley, Adjoint quasi-differential operators of Euler

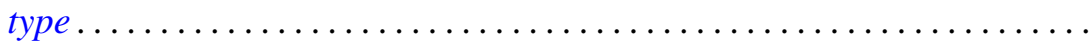

Don Deckard and Lincoln Kearney Durst, Unique factorization in power series rings and semigroups ........................... 239

Allen Devinatz, The deficiency index of ordinary self-adjoint differential operators..................................... 243

Robert E. Edwards, Operators commuting with translations ............ 259

Avner Friedman, Differentiability of solutions of ordinary differential equations in Hilbert space .............................. 267

Boris Garfinkel and Gregory Thomas McAllister, Jr., Singularities in a variational problem with an inequality ......................

Seymour Ginsburg and Edwin Spanier, Semigroups, Presburger formulas,

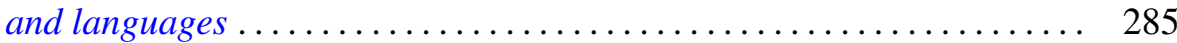

Burrell Washington Helton, Integral equations and product integrals . . . . . . 297

Edgar J. Howard, First and second category Abelian groups with the n-adic topology.........................................

Arthur H. Kruse and Paul William Liebnitz, Jr., An application of a family homotopy extension theorem to ANR spaces.

Albert Marden, I. Richards and Burton Rodin, On the regions bounded by homotopic curves

Willard Miller, Jr., A branching law for the symplectic groups ...

Marc Aristide Rieffel, A characterization of the group algebras of the finite

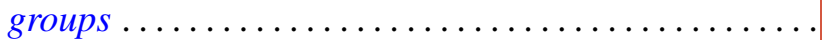

P. P. Saworotnow, On two-sided $H^{*}$-algebras

John Griggs Thompson, Factorizations of p-solvable groups ...

Shih-hsiung Tung, Harnack's inequalities on the classical Cartan

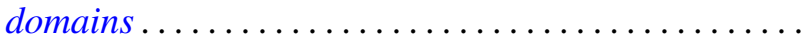

